\title{
Accounting Education - Between Digitalisation and the COVID-19 Pandemic Crisis
}

\author{
Professor Robert-Aurelian ȘOVA, PhD, Associate Professor Adriana Florina POPA, PhD \\ Bucharest University of Economic Studies, Romania
}

\begin{abstract}
The present article represents an analysis regarding the effects of the current challenges posed mainly by digitalisation, but also by the COVID-19 pandemic crisis, on professional bodies and the continuing professional development of their members. In the constant fight for adaptation and survival carried out both in their own interest and in that of their business clients, professional accountants must find solutions to make the best decisions and to optimize their activity in order to meet the current market requirements. There is a need for a long-term vision that focuses on the accounting education, based on the development of new accounting skills that go beyond the traditional ones and that may result in the transition from retrospection to forecasting.
\end{abstract}

Key terms: professional accountant, education, continuous professional development, digitalisation, pandemic

JEL Classification: A20, A29, M41, O33, H12

To cite this article: Robert-Aurelian Șova, Adriana Florina Popa, Accounting Education - Between Digitalisation and the COVID-19 Pandemic Crisis, CECCAR Business Review, No 11/2020, pp. 59-63, DOI: http://dx.doi.org/10.37945/cbr.2020.11.07

\section{Introduction}

We live in an everchanging world. The economy, education, technology, habits and mindsets are all affected one way or another by this reality. However, the important things don't change, we just have to adapt our manner of approach. From an economic point of view, we notice that the company, which must have the necessary resources to adapt to permanent changes and to face challenges, is at the centre of it all. The digital age lead to the change of the business models through technologization and automatization. Moreover, the COVID-19 pandemic has created unexpected problems for companies - financial, operational and staff-related difficulties regardless of their size and industry, impacting the way of action. In this context, the roles and abilities of professional accountants must evolve as a response to the requirements of the exterior environment, as they offer strategic advice to help companies ensure their going concern.

\section{International perspectives on the role of education}

Quality education is one of the 17 sustainable development goals of the United Nations' call to action to all the states in the world. These world-transforming goals are part of a model for creating a better and more sustainable future and represent a critical framework in the post pandemic recovery struggle (The United Nations, Sustainable Development Goals, https://www.un.org/sustainabledevelopment/sustainable-development-goals/).

Generally, a crisis is a stress test that challenges the resilience and equity of our education systems. This is one of the points of view expressed by the Organization for Economic Co-operation and Development (OECD) in one of its perspectives on education policy-Education Responses to COVID-19: An Implementation Strategy Toolkit. The application of an educational response to a crisis such as the one caused by the COVID-19 pandemic 
was and continues to be a challenge in the light of the current uncertainties. Education at a Glance is also a recognised source of news regarding the state of education worldwide, developed annually by the OECD, which provides key-information about the results of educational institutions, the impact of education on countries, the financial resources invested, the educational environment, the recorded progress, etc.

At the EU level, the interest in quality education is highlighted in the European Commission's Communication A Strong Social Europe for Just Transitions, which prepares the way for an Action Plan to implement the European Pillar of Social Rights, through EU initiatives and a wide-ranging debate with all EU countries, regions and partners: The European Parliament and national parliaments representing the population of Europe, the European Council and the national governments representing the European countries, the social partners representing the employers and employees and the civil society that expresses essential opinions on the current subjects.

Against the backdrop of the problems that we currently face - climate change, environmental degradation, digital economy, demographic change, etc. - , the future-readiness of people achieved through education, training and quality skills is one of the solutions. According to this Communication, skills are the key to the future, and education and training are essential in order to gain them. For example, for the purpose of developing advanced digital skills, actions have been developed and implemented, such as those adopted at EU level, respectively, the Digital Europe programme and the Updated Digital Education Action Plan, that contribute to the implementation of technology in economy and to sharing the best practices.

Education, training and life-long learning are one of the twenty underlying principles of the European Pillar of Social Rights. According to the first principle, everyone has the right to quality and inclusive education, training and life-long learning in order to maintain and acquire skills that enable them to participate fully in society and manage successfully transitions in the labour market. This Pillar represents the social strategy of the European Union to ensure the transition towards climate neutrality, digitalization and demographic changes as well as the recovery after the COVID-19 pandemic.

Particularly, promoting accounting education is an integral part of the International Federation of Accountants' (IFAC) vision, according to which the global accounting profession is recognised as being essential for strong and sustainable organizations, financial markets and national economies. Professional accountants that are competent, reliable and dedicated to life-long learning are the basis of this vision. In order to remain relevant in an ever-changing environment, they must prove more and more that they have abilities that surpass the accounting skills recognised in our days.

In order for accounting education to adequately respond to the challenges created by the changes in skills and abilities, IFAC captured the evolution of the profession as follows:
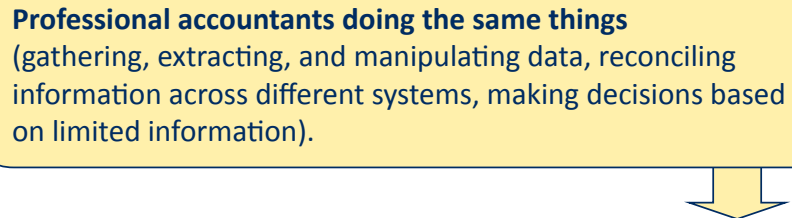

Professional accountants doing the same things differently (use of automation and leveraging communication technologies, based on self-learning and personal exploration).

LL

Professional accountants doing different things (derived from present actions, that imply requalification and improvement, with a focus on relevant competencies, including business acumen, behavioural competence, digital acumen, data integration, synthesis, analysis, communication).

Source: Adapted from Vitale, 2020. 


\section{Professional bodies and their role in the digital world}

The digitalisation of transactions rapidly transforms the reality in the field and the type of work, causing professional accountants to transition from a retrospective approach to a forecast-based one. The acceptance of new technologies such as big data, blockchain, bitcoin, cloud computing, eXtensible Business Reporting Language, mobile phone technology, artificial intelligence, software applications and social media allows one to understand the power of information in a data-based world and to harness it efficiently. Moreover, it seems that the COVID-19 pandemic has forced an important change in the professional development of professional accountants, technology playing an important part in this process. But has the pandemic caused this change itself or has it just sped up its development?

Following a series of consultations, on the most urgent aspects for the profession, organized by the Chartered Professional Accountants of Canada (CPA) between professional accountants and the stakeholders from this country (CPA Canada, Foresight: Reimagining the Profession Makes Urgent Case for Change, https://www. cpacanada.ca/en/foresight-initiative), the conclusion reached was that in this new world it is necessary to explore how the profession will need to pivot to new ways of doing things, including:

- measuring value beyond the financial statements in order to identify societal expectations;

- harnessing the power of vast quantities of data in order to make decisions and establishing new models of governance and decision-making;

- developing new skills and competencies;

- protecting integrity, trust and ethics.

Professional bodies play an active role in the development of their members and in helping them become future-ready. In the context of the current medical crisis that has had a direct impact on economic life, continuous professional development must ensure the required business skills and be flexible and relevant, while providing life-long learning opportunities.

Thus, the following questions arose: Are we future ready? What skills do we require in order to be futureready? Are the skills considered necessary until now sufficient? The concept of future ready accountant or of future ready accounting profession has been advanced by IFAC (2019) and has rapidly turned into a current requirement, with an impact on the need to be permanently up to date with the key accounting issues and the permanent tax changes and to help employers and clients face accounting and financial challenges in the post pandemic period.

\section{$\rightarrow$ Continuous professional development, between tradition and the need to adapt to the effects of the crisis}

Drawing on the OECD's (2020) perspective on the next steps to be taken in the education systems, which focuses on three aspects, namely the assurance of quality, fairness and welfare, we consider that these steps can be adapted to the continuous professional development. Therefore, these steps transposed in the case of professional bodies, in general, and of the professional body of Romania, in particular, are presented in the next figure:

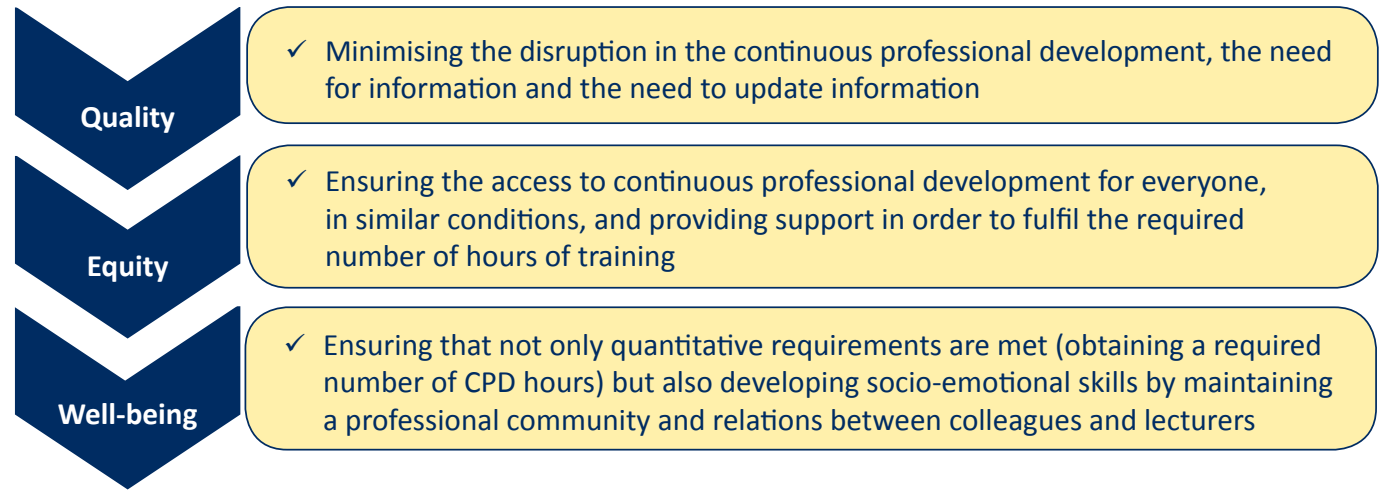

Source: Adapted from OECD, 2020. 
Not only has the need to share information and knowledge not diminished, but, on the contrary, it has become more and more important in countering the effects of the crisis caused by the pandemic. Thus, was born the idea of developing an online information hub, with resources, good practices, tips and advice (https:// covid-19.ceccar.ro/, https://www.ifac.org/knowledge-gateway/discussion/covid-19-resources-ifacs-network, https://www.oecd.org/coronavirus/en/, https://future.aicpa.org/topic/covid-19, https://www.cpacanada.ca/ en/members-area/covid-19-resources, etc.).

The COVID-19 pandemic has caused significant disturbances in the classical education and training system and has led to the need to implement rapid and innovative digital measures. For example, as a first adaptation response we recall the transition from face-to-face education, in classrooms, to virtual education, through online courses, webinars, videoconferences, online conferences, TV shows, electronic mail and telecommunication. The purpose of these alternatives is to keep the continuous professional development accessible and adaptable in these restrictive conditions.

The unstoppable progress of technology has enabled the removal of some barriers, such as those of physical meetings. The alternatives are virtual meetings, organized via online platforms (Zoom.us, Cisco Webex, Google Meet, etc.) or hybrid ones, which involve combining physical and virtual elements (physical or online access through simultaneous live transmissions).

Despite the advantages of virtual alternatives - removing geographical and time barriers, access to information in real time, smaller organizational investments and costs -, physical contact has always been very important. Closeness and face to face meetings represent powerful communication and connection instruments, that have direct implications on the sense of belonging to a professional body or a community. The direct transmission of messages from lecturer to participant, the direct dialogue and nonverbal communication contribute to a correct revision of information and to a greater degree of understanding.

\section{The case of the professional body of Romania}

Taking these trends into account, the Body of Expert and Licensed Accountants of Romania makes the necessary steps in order to adapt to the new expectations regarding the skills and roles of accountants. Change is on its way, the inevitable cannot be postponed, which gives rise to the question: Are the actions taken enough to build a sustainable professional accounting body for the future?

For CECCAR the first step was understanding the importance of preparing future-ready accountants. The next step was to make accounting education a strategic priority and an indicator for all activities undertaken. Using an integrated approach, the actions taken focused on three domains:

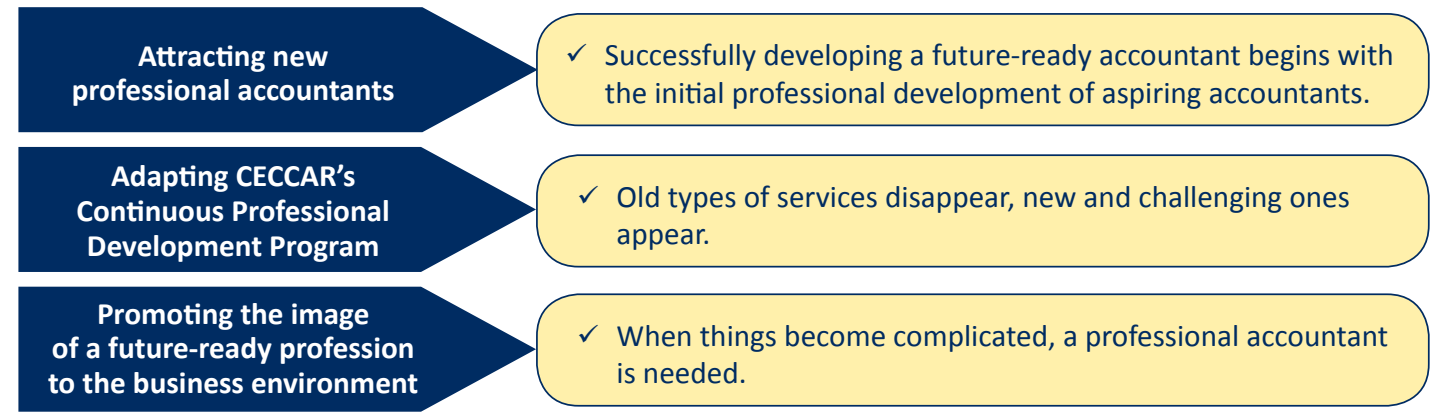

Source: Popa \& Şova, 2020.

In accordance with IFAC's perspective, a long-term vision for accounting education is necessary, and this must include attracting new members, keeping existing members and increasing the demand for professional accountants by proving their value and adaptability to change.

In doing so, the professional body supports accounting education in Romania, in order to offer career advice to young people and to represent the accounting profession, working closely with contractors, institutions and regulators. 
Is CECCAR ready for the future? Yes, by building a future-ready profession. The actions undertaken confirm the relevance and sustainability of the organization for the future, as it faces new challenges proactively and relies on its history of almost 100 years.

\section{Conclusions}

The current context requires measures to be taken rapidly and efficiently. Digitalization changed the business world more than anyone could have imagined, generating direct and indirect effects on accounting education, on the way in which the profession is perceived and on the need for a continuous professional development that can keep up with current and future needs.

Despite the global scale of the pandemic, there is no single generally applicable way in which to successfully overcome the crisis. We agree with the necessity and efficiency of implementing certain measures such as those proposed by OECD in its strategy for education and training, which include:

- developing a vision that recognizes the crisis and its implications, based on the key educational principles described previously: quality, equity and well-being;

- adapting the way in which the educational process is organized - based on the assessment of resources and taking into account the points of view of stakeholders;

- adopting a clear and coherent implementation strategy - in terms of time, responsibilities and resources;

- analysing the way in which technology and hybrid training models can be efficient;

- using the experience gained from the crisis in order to improve existing methods.

We all have to regard the current challenges that we face as having a positive effect: enabling us to discover ourselves, to reposition ourselves and, why not, to reinvent ourselves as professional accountants, for now but especially for the future.

\section{References}

1. Popa, A.F., Șova, R.A. (2020), Is the Romanian Accountancy Profession Ready for the Future? Yes!, https://www.ifac.org/knowledge-gateway/developing-accountancy-profession/discussion/romanianaccountancy-profession-ready-future-yes.

2. Vitale, A.-M. (2020), Re-imagining the Future Accountant - Our Call to Action, https://www.ifac.org/ knowledge-gateway/preparing-future-ready-professionals/discussion/re-imagining-future-accountantour-call-action.

3. CPA Canada, Foresight: Reimagining the Profession Makes Urgent Case for Change, https://www.cpacanada. ca/en/foresight-initiative.

4. European Commission, Communication from the Commission to the European Parliament, the Council, the European Economic and Social Committee and the Committee of the Regions "A Strong Social Europe for Just Transitions", https://eur-lex.europa.eu/legal-content/RO/TXT/?uri=CELEX:52020DC0014\& qid $=1580400520904$.

5. European Commission, The European Pillar of Social Rights in 20 Principles, https://ec.europa.eu/ commission/priorities/deeper-and-fairer-economic-and-monetary-union/european-pillar-social-rights/ european-pillar-social-rights-20-principles_en.

6. IFAC (2019), Future-Ready Accountants in Business, https://www.ifac.org/knowledge-gateway/preparingfuture-ready-professionals/publications/future-ready-accountants-business.

7. OECD (2020), Education Responses to Covid-19: An Implementation Strategy Toolkit, OECD Education Policy Perspectives, No. 5, https://doi.org/10.1787/81209b82-en.

8. OECD, Education at a Glance, https://www.oecd.org/education/education-at-a-glance/.

9. The United Nations, Sustainable Development Goals, https://www.un.org/sustainabledevelopment/ sustainable-development-goals/.

10. Face-to-face vs. Virtual Events vs. Hybrid, https://www.virtwayevents.com/face-to-face-virtual-hybrid-events/. 